\title{
High-throughput system for screening of Monascus purpureus high-yield strain in pigment production
}

\author{
Jun Tan, Ju Chu*, Yonghong Wang, Yingping Zhuang and Siliang Zhang
}

\begin{abstract}
Background: An economical and integrated high-throughput primary screening strategy was developed for high-aerobic microbe Monascus purpureus cultivation. A novel and effective mixture culture method was proposed and used to realize the whole mutant library being high-throughput screened after mutagenesis.

Results: The good correlation of fermentation results between differing-scale cultivations confirmed the feasibility of utilizing the 48-deep microtiter plates (MTPs) as a scale-down tool for culturing high-aerobic microbes. In addition, the fluid dynamics of 24-, 48-, and 96-deep MTPs and 500-mL shake flask were studied respectively using the computational fluid dynamic (CFD) tool ANSYS CFX 11.0 to get better understanding of their turbulent regimes. Conclusions: The by-product citrinin production had no significant change while the pigment production had improved. As a result, the high-yield strain T33-6 was successfully screened out and the pigment was more than $50 \%$ higher than that of the parental strain in the shake flask.
\end{abstract}

Keywords: Monascus; High-throughput screening; Mixture cultivation; Computational fluid dynamics

\section{Background}

Natural colorants derived from plants and microorganisms have recently gained popularity over synthetic coloring agents because of undesirable toxic effects including mutagenicity and potential carcinogenicity in some cases [1]. Monascus pigments produced by Monascus purpureus (M. purpureus) fermentation are now used in processed seafood, sausages, and sauces in Asia to replace some food additives such as cochineal, potassium nitrate, and nitrites [2-4]. However, M. purpureus is also a toxigenic strain that can produce the nephrotoxic and hepatotoxic mycotoxin citrinin which greatly limits the wide application of the Monascus-related products [5-7]. Monascus pigments are safe, especially characterized with high protein adhesion and heat stability and can be used in a wide $\mathrm{pH}$ range $[8,9]$. Hence, the investigations on the improvement of the pigment production are of commercial importance in the food coloration market.

\footnotetext{
* Correspondence: juchu@ecust.edu.cn

State Key Laboratory of Bioreactor Engineering, East China University of Science and Technology, 130 Meilong Road, P.O. Box 329\#, Shanghai 200237, People's Republic of China
}

The high-yield strain is a key factor for the production of fermented foods. However, most traditional fermentation experiments were performed in shake flasks. The extraction of Monascus pigments was time consuming and inconvenient for treatment of large numbers of samples. A large amount of material was required, so it was uneconomic and impractical for high-throughput system. Therefore, a simple high-throughput primary screening strategy that can culture and evaluate a large number of isolates simultaneously with a fair degree of accuracy and reproducibility becomes imperative [10]. Microtiter plates (MTPs) are attractive for high-throughput cultivation due to its small working volume and high degree of parallelization $[11,12]$. Oxygen mass transfer rate (OTR) and mixing studies in MTPs have been extensively reported $[13,14]$. It proved that the square-shaped vessel can provide higher OTR. Forty-eightdeep-well microtiter plates (48-deep MTPs) were used in the present high-throughput strategy, and the correlation was good with shake flasks. Furthermore, the success of any strain improvement program mainly depends on the number of positive isolates that can be screened after mutagenic treatment [15]. However, only a small part of mutants

\section{国}

(C) 2014 Tan et al.; licensee Springer. This is an open access article distributed under the terms of the Creative Commons Attribution License (http://creativecommons.org/licenses/by/4.0), which permits unrestricted use, distribution, and reproduction in any medium, provided the original work is properly credited. 
selected randomly have the chance to be screened in traditional screening method [16,17].

In this paper, the mixture cultivation was effectively proposed to realize the whole mutant library of high-aerobic microbe $M$. purpureus being high-throughput screened after mutagenesis integrating the subsequent highthroughput pigment microassay. The high-yield mixture in one well of the microtiter plate was screened out first. The subsequent isolation of the desirable high-yield colonies was further selected and screened from this specific high-yield mixture. The method greatly increased screening efficiency compared with conventional method.

\section{Methods}

\section{Microorganisms}

M. purpureus M-403 used in this study was a parent strain preserved in our laboratory at $4^{\circ} \mathrm{C}$ on peptonemalt extract agar slants $(\mathrm{g} / \mathrm{L})$ : peptone 30.0 , malt extract 12.0, and agar 20.0.

Seed medium adjusted to $\mathrm{pH} 4.2$ by lactic acid was composed of $(\mathrm{g} / \mathrm{L})$ : starch $30.0, \mathrm{NaNO}_{3} 2.5, \mathrm{KH}_{2} \mathrm{PO}_{4} 2.5$, $\mathrm{MgSO}_{4} \cdot 7 \mathrm{H}_{2} \mathrm{O} 1.3$, soybean meal 10.0 , and corn steep liquor 15.0. Fermentation medium adjusted to $\mathrm{pH} 4.5$ was composed of $(\mathrm{g} / \mathrm{L})$ : glucose 40.0, peptone 5.0, $\mathrm{NaNO}_{3}$ 3.0, $\mathrm{KH}_{2} \mathrm{PO}_{4}$ 1.5, and $\mathrm{MgSO}_{4} \cdot 7 \mathrm{H}_{2} \mathrm{O}$ 1.0. Media were sterilized by autoclaving for $25 \mathrm{~min}$ at $121^{\circ} \mathrm{C}$.

\section{Culture of microorganism}

\section{Traditional culture in shake flask}

M. purpureus M-403 and its mutants were precultured in $500-\mathrm{mL}$ shake flask containing $50 \mathrm{~mL}$ seed medium at $33^{\circ} \mathrm{C}$ on a rotary shaker at $220 \mathrm{rpm}$ for $42 \mathrm{~h}$ (50-mm shaking diameter, 30/300, ZHWY-3212, Zhicheng Analytical Instrument Manufacturing Co., Ltd., Shanghai, China). Nine percent $(\mathrm{v} / \mathrm{v})$ precultures were inoculated in $500-\mathrm{mL}$ shake flask containing $50 \mathrm{~mL}$ fermentation medium at $33^{\circ} \mathrm{C}, 220$ $\mathrm{rpm}$. The samples were taken every $6 \mathrm{~h}$. All the experiments were carried out in triplicate at least.

\section{Microculture in 48-deep MTPs}

M. purpureus M-403 and its mutants were inoculated with toothpicks in 48-deep MTPs containing $1.0 \mathrm{~mL}$ seed medium at $33^{\circ} \mathrm{C}$ on a rotary shaker at $220 \mathrm{rpm}$ for $42 \mathrm{~h}$. Nine percent $(\mathrm{v} / \mathrm{v})$ precultures were inoculated in the corresponding wells of new 48-deep MTPs containing $1.0 \mathrm{~mL}$ fermentation medium. The other culture conditions were the same as shake flasks.

\section{High-throughput system for screening Mutagenesis procedure}

M. purpureus (M-403) was subjected to mutagenesis using UV irradiation and $\mathrm{LiCl}$ treatment. M-403 was grown on agar slant at $33^{\circ} \mathrm{C}$ for 7 days. A piece of $2 \times 2 \times 3(\mathrm{~cm} \times$ $\mathrm{cm} \times \mathrm{mm}$ ) slant was dug into the homogenizer, gently homogenized with $10 \mathrm{~mL}$ sterile water to obtain homogeneous hypha suspension. All the hypha suspension was collected to expose to UV irradiation at $254 \mathrm{~nm}$ for $3 \mathrm{~min}$ at a distance of $20 \mathrm{~cm}$ in petri dish, and the isometric $10 \mathrm{~mL}$ $1.2 \% \mathrm{LiCl}$ solution was added in the petri dish, mixed, and contacted for $20 \mathrm{~min}$, which resulted in $90 \%$ kill rate at least.

\section{Mixture cultivation and high-throughput screening}

Firstly, screen the high-yield mixture from the mutant library: $20 \mathrm{~mL}$ treated hypha suspension was equally allotted into the 48-deep MTPs, roughly 30 plates were needed. Fifteen-microliter mutant suspension called a mixture, was cultured in a well containing $1.0 \mathrm{~mL}$ seed medium shaking at $220 \mathrm{rpm}$ for $42 \mathrm{~h}$ at $33^{\circ} \mathrm{C}$. Nine percent $(\mathrm{v} / \mathrm{v})$ seed culture was inoculated in another sterile corresponding well of 48deep MTPs at $220 \mathrm{rpm}$ for $48 \mathrm{~h}$; the remaining seed cultures were preserved in $4^{\circ} \mathrm{C}$ refrigerator with parafilm until assay results were obtained. The pigment was determined by highthroughput determination. It can be speculated that the more high-yield mutants dominate in the mixture, the higher pigment production could be observed from the corresponding wells. The subsequent isolation of the desirable colonies from the high-yield mixture should have much higher probability than that only isolated from the parts of treated hypha suspension directly by traditional dilution-plate method.

Secondly, isolate the high-yield strain from the highyield mixture: The preserved seed of high-yield mixture, approximately $300 \mu \mathrm{l}$, was inoculated on the fresh slant for 7 days at $33^{\circ} \mathrm{C}$. Single colonies were isolated by a traditional dilution-plate method. The integrated procedure chart is shown in Figure 1.

\section{Extraction of pigments \\ Traditional determination}

Extraction of pigments from 500-mL shake flask: $1 \mathrm{~mL}$ of the culture broth was mixed with $9 \mathrm{~mL}$ of $70 \%(\mathrm{v} / \mathrm{v})$ ethanol in a test tube, rest for $15 \mathrm{~min}$; the supernatant was filtered by a filter paper ( $45 \mu \mathrm{m}$, Xinhua Paper Industry Co., Ltd., Hangzhou, China); and the pigment concentrations were measured by a spectrophotometer at $517 \mathrm{~nm}$ after dilution. The pigment production $(\mathrm{U} / \mathrm{mL})=\mathrm{OD}_{517} \times$ dilution factor.

\section{High-throughput determination}

Extraction of pigments from 48-deep MTPs: $0.1 \mathrm{~mL}$ of the culture broth was mixed with $0.9 \mathrm{~mL}$ of $70 \%(\mathrm{v} / \mathrm{v})$ ethanol in new 48-deep MTPs, rest for $15 \mathrm{~min}$ and the supernatant was obtained by MTP centrifuge (TDZ5WS, Jiachuang Biotechnology Co., Ltd., Shanghai, China; $3,000 \times g, 5 \mathrm{~min}$ ) and pipetted $300 \mu \mathrm{l}$ into each well of a new 96-well microtiter plate. The pigment concentrations were measured by a microplate reader (Multiskan Go, Thermo Fisher Scientific Inc., Massachusetts, MA, USA) at $517 \mathrm{~nm}$ after dilution. The pigment production $(\mathrm{U} / \mathrm{mL})=\mathrm{OD}_{517} \times$ dilution factor. 


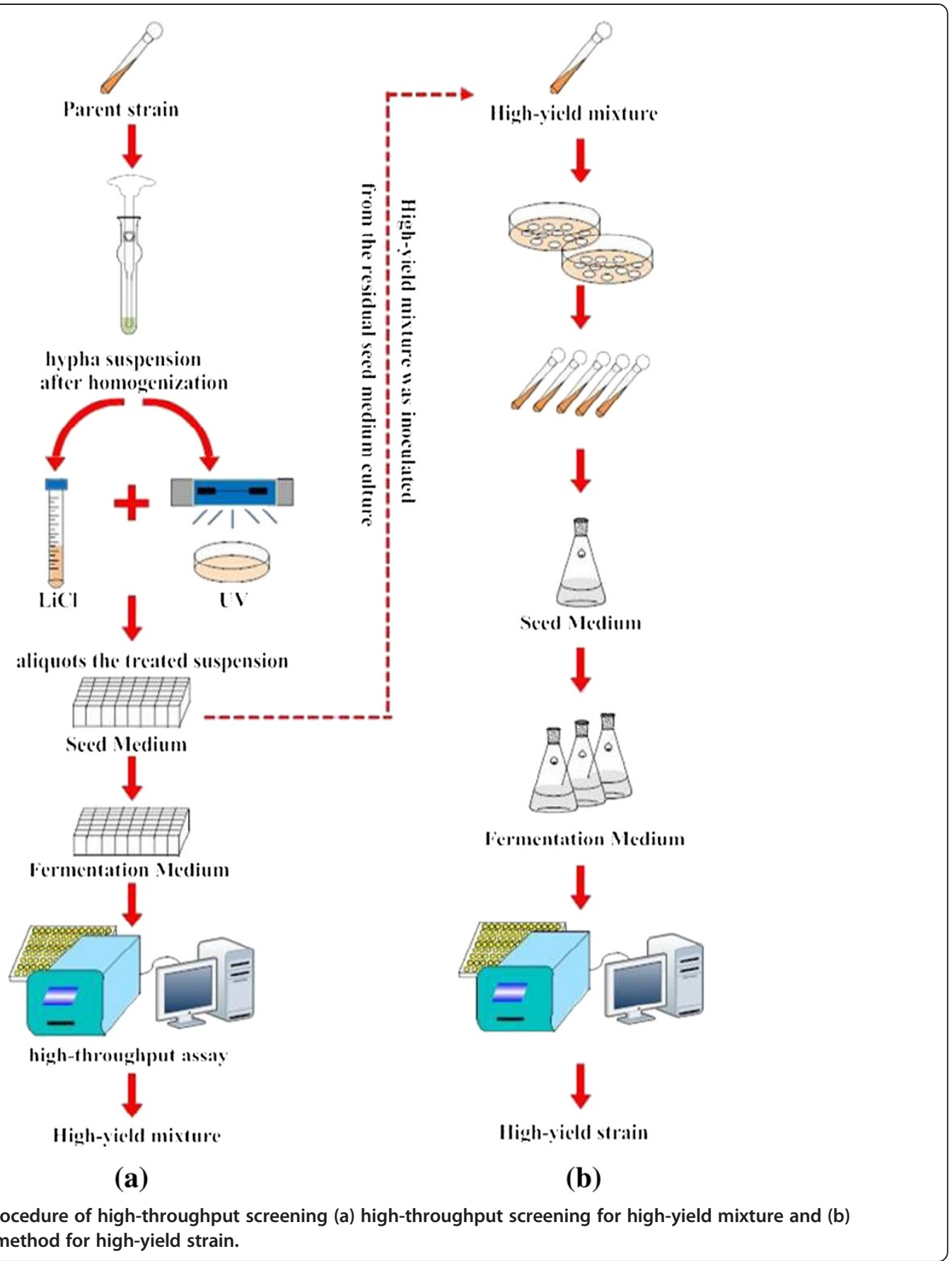

\section{Citrinin analysis}

Pure citrinin was purchased from Sigma Chemical Company, St. Louis, MO, USA. All solvents used were highperformance liquid chromatography (HPLC) grade. Citrinin was extracted by methanol, $1 \mathrm{~mL}$ fermentation broth mixed fiercely with the same volume of methanol for $10 \mathrm{~min}$ and centrifuged at $15,000 \times g$ for $20 \mathrm{~min}$. The supernatant was determined by HPLC (Agilent 1100 Series, Shanghai, China). The samples were separated on a TSK-gel ODS-100S C18 column at a flow rate of $1 \mathrm{~mL} / \mathrm{min}, 28^{\circ} \mathrm{C}$, automatic injector
$50 \mu$ l. Fluorescence detection was performed with a FP-920 fluorescence detector (Jasco Corp., Tokyo, Japan) set at 331-nm excitation wavelength and 500-nm emission wavelength. The mobile phase consisted of acetonitrile/water $(35 / 65, \mathrm{v} / \mathrm{v})$, and the $\mathrm{pH}$ was 2.5 adjusted by phosphoric acid.

\section{$k_{\mathrm{L}} a$ value measurements}

The sulfite oxidation method [18] was employed to determine the $k_{\mathrm{L}} a$ in MTPs and shake flask. The sulfite solution system contained $0.5 \mathrm{M}$ sodium sulfite, $10^{-7} \mathrm{M}$ 
cobalt sulfate, $0.012 \mathrm{M} \mathrm{Na}_{2} \mathrm{HPO}_{4} / \mathrm{NaH}_{2} \mathrm{PO}_{4}$ phosphate buffer ( $\mathrm{pH}$ 8.0), and $2.4 \times 10^{-5} \mathrm{M}$ bromothymol blue. The initial $\mathrm{pH}$ was adjusted to 8.0 using $2.0 \mathrm{M}$ sulfuric acid. The $\mathrm{pH}$ of the sulfite solution remained at an almost constant value of $\mathrm{pH} 8.0$ before dropping sharply to a value of $\mathrm{pH}$ 5.0 at the end of the reaction. The time of the color changes from blue to yellow was measured accurately to calculate the $k_{\mathrm{L}} a$ value of MTPs and shake flask. All the experiments were performed at $220 \mathrm{rpm}$, five parallelisms at least.

\section{Results and discussion}

\section{Performance evaluation of MTPs and shake flask}

Computational fluid dynamic (CFD) methods based on the Navier-Stokes equation have become a powerful tool to predict the fluid flow and homogenization in stirred tanks $[19,20]$. Many papers published the simulation methods of mixing [21], mass transfer [22], and shear environment [23] in different kinds of stirred tanks. The fluid dynamics of 24-, 48-, and 96-deep MTPs and 500$\mathrm{mL}$ shake flask were studied respectively using the CFD tool ANSYS CFX 11.0 to get better understanding of their turbulent regimes. Power consumption, shear strain, and oxygen mass transfer coefficient were calculated by numerical simulation, and the results were verified by experimental data. The parameter values are shown in Table 1. The shear strain presented the shear force in MTPs and shake flask, the result revealed that the shear effect of 24- and 48-deep MTPs was superior or comparable to shake flask, while 96-deep MTPs were unsatisfied. Figure 2 shows the distribution of shear force in MTPs and shake flask. The maximum shear force distributed near the wall of 24- and 48-deep MTPs and $500-\mathrm{mL}$ shake flask, while the maximum shear force mainly distributed at the bottom of the 96-deep MTPs. It indicated that the liquid mixing was insufficient in the 96-deep MTPs, directly influenced the oxygen transfer. The properties of 24- and 48-deep MTPs were comparable with $500-\mathrm{mL}$ shake flask. Furthermore, the power consumption of 24- and 48-deep MTPs was only 5\% of the shake flask. These parameters illustrated that the MTPs were very practical equipment for high-throughput screening. Considering the oxygen transfer capability and the screening throughput, 48-deep MTPs were selected for M. purpureus cultivation.

\section{High-throughput screening system}

The general method for supernatant collection was time consuming and laborious for the sample treatment, especially for the samples from 48-deep MTPs which was impractical for rapid and high-throughput screening. In order to develop a simple, rapid, and high-throughput screening strategy, it is preferential to establish a simple and accurate analytical method. Therefore, 48-deep MTPs, MTP centrifuge, and microplate reader were employed to solve the problem. Thousands of samples could be determined simultaneously in a short time, meanwhile, could also save more material consumption.

Commercially available standard pigment (98.2\%, Sigma) was used to determine the maximum absorbance by microplate reader from 300 to $700 \mathrm{~nm}$; the pigments have maximum absorbance at $517 \mathrm{~nm}$.

Twenty mutants derived from M. purpureus M-403 were fermented in shake flasks, the Monascus pigment was determined by a spectrophotometer and microplate reader. The data based on a microplate reader were higher than the results from a spectrophotometer (Figure 3a), but the high correlation coefficient $(0.95)$ was obtained by statistical analysis. This high-throughput assay could be effectively used for the determination of Monascus pigment instead of traditional methods. The comparisons of differing-scale cultivations are assessed as shown in Figure $4 \mathrm{~b}$. The strain $\mathrm{M}$ 403 was fermented in shake flasks and in 48-deep MTPs, respectively, both the Monascus pigments were determined by a microplate reader. The comparison results between differing-scale cultivations were generally good (Figure 3b). Both Monascus pigments in 48-deep MTPs and shake flasks were increased to their maximum values at $42 \mathrm{~h}$ and were kept constant until $78 \mathrm{~h}$. Although the pigment productions in shake flasks were higher than that in 48-deep MTPs, the results had the same tendency. The correlation coefficient was 0.98 by statistical analysis. The data suggested that the 48-deep MTPs could be used as a scaledown tool for high-aerobic microbe screening applications. The data also illustrated that this scale-down system could be effectively used to determine pigment production. Thus, we had developed an integrated high-throughput screening strategy combined the 48-deep MTPs culture system with the microplate assay. All experiments were performed in triplicate.

Table 1 The performance evaluation of MTPs and shake flask

\begin{tabular}{|c|c|c|c|c|c|}
\hline & Filling volume $(\mathrm{mL})$ & $k_{\mathrm{L}} a(1 / \mathrm{h})^{\mathrm{a}}$ & $\mathrm{P} / \mathrm{V}\left(\mathrm{W} / \mathrm{m}^{3}\right)^{\mathrm{b}}$ & $\operatorname{SSR}(1 / \mathrm{s})^{\mathrm{c}}$ & $k_{\mathrm{L}} a(1 / \mathrm{h})^{\mathrm{d}}$ \\
\hline 24-deep MTPs & 1.2 & 176 & 79.1 & 76.8 & 148.8 \\
\hline 48-deep MTPs & 0.7 & 170 & 73.8 & 85.3 & 144.3 \\
\hline 96-deep MTPs & 0.5 & 71.4 & 7.3 & 27.8 & 58.77 \\
\hline $500 \mathrm{~mL} \mathrm{SF}$ & 30 & 130.1 & 1348.9 & 61.4 & 150.7 \\
\hline
\end{tabular}

${ }^{a} k_{L} a$ : oxygen mass transfer coefficient calculated by numerical simulation; ${ }^{b} \mathrm{P} / \mathrm{V}$ : power consumption per unit volume; ${ }^{\mathrm{c} S S R}$ : shear strain; ${ }^{\mathrm{d}} \mathrm{k}_{\mathrm{L}} \mathrm{a}$ : oxygen mass transfer coefficient determined by experiment. 
a SSSR
Contour 1
\begin{tabular}{|l|}
$3.765 \mathrm{e}+002$ \\
$3.389 \mathrm{e}+002$ \\
$-3.012 \mathrm{e}+002$ \\
$2.636 \mathrm{e}+002$ \\
$-2.259 \mathrm{e}+002$ \\
$-1.883 \mathrm{e}+002$ \\
$-1.506 \mathrm{e}+002$ \\
$-1.130 \mathrm{e}+002$ \\
$7.531 \mathrm{e}+001$ \\
$3.765 \mathrm{e}+001$ \\
$1.336 \mathrm{e}-013$
\end{tabular} b [s^-1] Contour 1 $2.801 \mathrm{e}+002$ $2.521 \mathrm{e}+002$ $2.241 \mathrm{e}+002$ $1.961 \mathrm{e}+002$ $1.681 \mathrm{e}+002$ $1.401 \mathrm{e}+002$ $1.120 \mathrm{e}+002$ $8.403 e+001$ $5.602 \mathrm{e}+001$ $2.801 \mathrm{e}+001$ $5.390 \mathrm{e}-007$ [s^-1]

C

SSSR Contour 1 $5.517 \mathrm{e}+001$ $4.966 \mathrm{e}+001$ $4.414 \mathrm{e}+001$ $3.862 e+001$ $3.310 \mathrm{e}+001$ $2.759 \mathrm{e}+001$ $2.207 \mathrm{e}+001$ $1.655 \mathrm{e}+001$ $1.103 e+001$ $5.517 \mathrm{e}+000$ $7.891 \mathrm{e}-017$ [s^-1]

d SSSR $1.127 \mathrm{e}+002$ $-1.014 \mathrm{e}+002$
$-9.013 \mathrm{e}+001$
$-7.887 \mathrm{e}+001$
$6.760 \mathrm{e}+001$
$-5.633 \mathrm{e}+001$
$-4.507 \mathrm{e}+001$
$3.380 \mathrm{e}+001$
$2.253 \mathrm{e}+001$
$1.127 \mathrm{e}+001$
$8.261 \mathrm{e}-013$

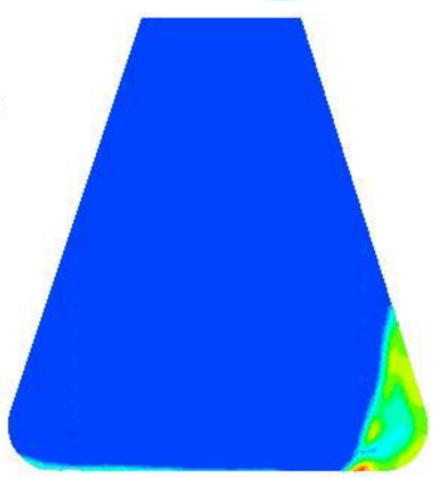

Figure 2 Shear force simulation profile of MTP and shake flask: (a) 24-deep MTPs, (b) 48-deep MTPs, (c) 96-deep MTPs, and (d) shake flask.

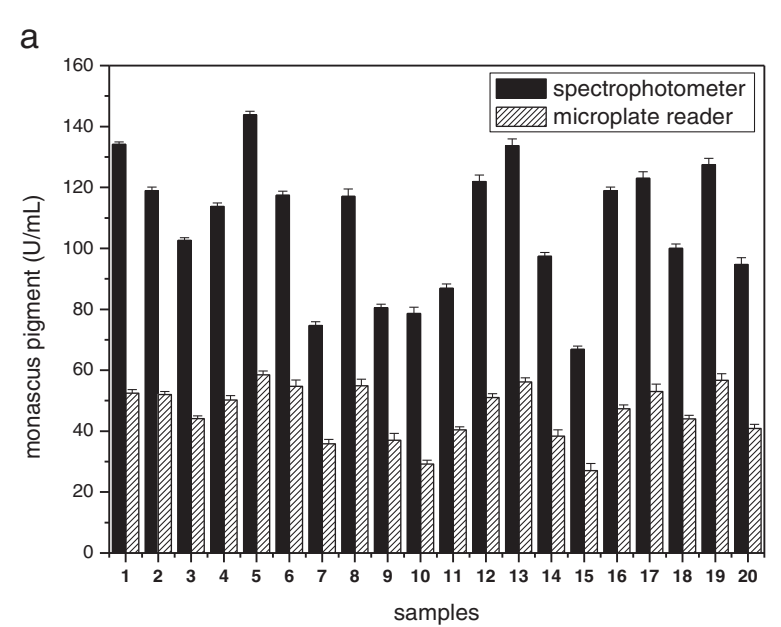

b

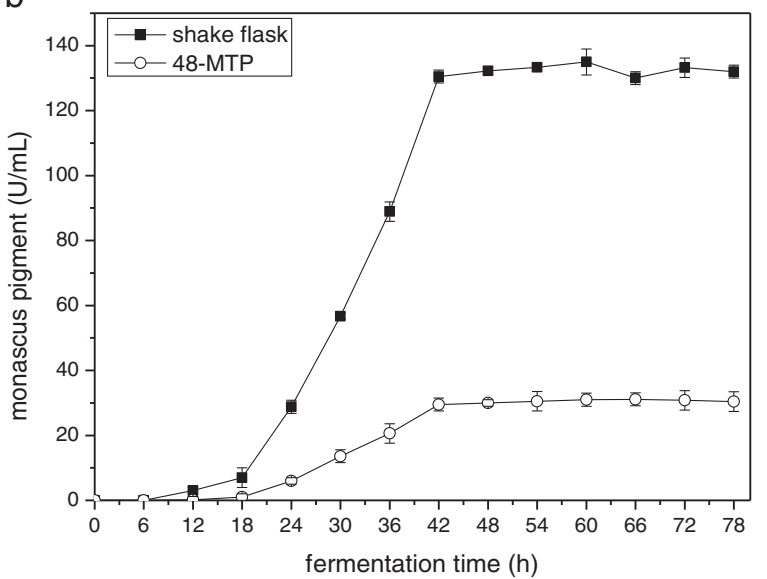

Figure 3 Monascus pigment determined by spectrophotometer and microplate reader and comparison of Monascus pigment fermented by $M$. purpureus M-403. Monascus pigment

determined by spectrophotometer and microplate reader (a) and comparison of Monascus pigment fermented by M. purpureus M-403 between shake flasks and 48-deep MTPs (b).

High-throughput screening for $M$. purpureus high-yield strain Figure 4a shows the results of mutagenic treatment, out of 1,400 mixtures in 48-deep MTPs, 125 mixtures could be determined the pigment production by a microplate reader. The dashed line stands for the pigment production of parent strain M-403 $(29.2 \mathrm{U} / \mathrm{mL})$. The pigment productions of $20 \%$ mixtures were comparable to that of the parent strain; 15 mixtures were found to possess pigment production at least $20 \%$ higher than that of the parent strain. Among these mixtures, the production of the high-yield mixture T33 was $44.5 \mathrm{U} / \mathrm{mL}$, nearly $50 \%$ higher than that of the parent strain. The corresponding seed culture well of the $\mathrm{T} 33$ preserved in $4^{\circ} \mathrm{C}$ refrigerator was traced back, and all the remaining seed culture of T33 was inoculated on the fresh slant timely for further single colony isolation. 


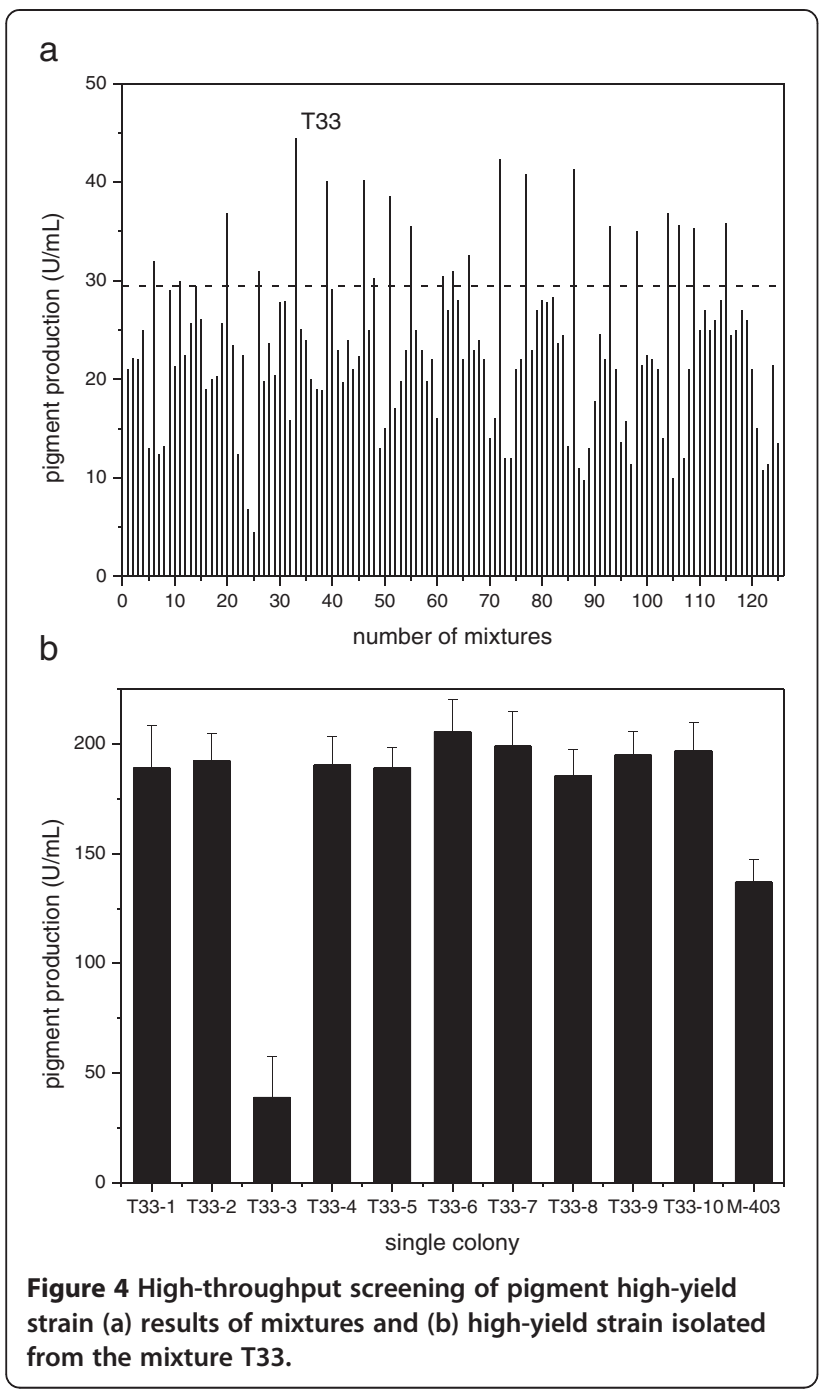

Among the colonies isolated from the high-yield mixture T33, ten available colonies were selected by our practical experience and their submerged cultivations in shake flasks were carried out with the parent strain (M-403) as the control (Figure 4b). Except colony T33-3, the productions of other nine colonies were almost $190.0 \mathrm{U} / \mathrm{mL}$ averagely, higher than that of the parent strain $(137.0 \mathrm{U} / \mathrm{mL})$. There was only a small part of low-yield mutants mixed in the high-yield mixture, so there was a high possibility to isolate the desired strain from the high-yield mixture compared with traditional shake flask screening. Repeated studies showed that the production of single colony T33-6 remained at the same level after several consecutive generations by submerged fermentation, three parallelisms for shake flasks at least. To the best of our knowledge, this is the first report to buildup an integrated HTS strategy for M. purpureus applications.
Table 2 Amount of citrinin detected in the samples of $M$. purpureus M-403 and T33-6

\begin{tabular}{lcc}
\hline & Parent strain $\mathbf{M - 4 0 3}$ & High-yield strain T33-6 \\
\hline Citrinin $(\mathrm{mg} / \mathrm{L})$ & 12.7 & 10.5 \\
RSD $(\%)$ & 4.21 & 3.72 \\
\hline
\end{tabular}

$\mathrm{RSD}$, relative standard deviation.

Comparison of citrinin production between mutant $M$. purpureus T33-6 and parent strain M. purpureus M-403

The parent strain and the high-yield strain were fermented in shake flasks; the amounts of citrinin are summarized in Table 2 . The amounts of citrinin produced by M. purpureus M-403 and T33-6 were $12.7 \mathrm{mg} / \mathrm{L}$ and $10.5 \mathrm{mg} / \mathrm{L}$, respectively; there was no significant change while the pigment production was improved, so this high-yield strain was satisfactory.

\section{Conclusions}

In summary, a novel high-throughput screening method was established for screening the whole mutant library of $M$. purpureus after mutagenesis. The high-yield strain T33-6 was screened out by mixture cultivation successfully. The production was $205.5 \mathrm{U} / \mathrm{mL}$ fermented in shake flasks, nearly $50 \%$ higher than that of parent strain. The amount of citrinin had no significant change produced by $M$. purpureus T33-6 $(11.9 \mathrm{mg} / \mathrm{L})$ and the parent strain $(12.7 \mathrm{mg} / \mathrm{L})$ while the pigment production had improved, so this high-throughput strategy was feasible. High-throughput technology played an important role in strain improvement screening, significantly increased throughput and reduced assay volume, efficaciously solve the low-throughput problem encountered in conventional strain screening. High-throughput screening field will continue to be promising and dynamic in the future.

\section{Competing interests}

The authors declare that they have no competing interests.

\section{Authors' contributions}

JT, JC, and YHW were in charge of the experiments and paper writing. YPZ and SLZ directed the study as the tutors. All authors read and approved the final manuscript.

\section{Acknowledgements}

This work was financially supported by a grant from the National High Technology Research and Development Program of China (863 program), No. 2012AA021201; the Major State Basic Research Development Program of China (973 program), No. 2012CB721006; National Major Scientific and Technological Special Project, No. 2012YQ15008709; and Research Fund for the Doctoral Program of Higher Education of China, No. 20110074110015.

Received: 23 June 2014 Accepted: 4 September 2014

Published online: 24 September 2014

\section{References}

1. Mapari SAS, Nielsen KF, Larsen TO, Frisvad JC, Meyer AS, Thrane U (2005) Exploring fugal biodiversity for production of water-soluble pigments as potential natural food colorants. Curr Opin Biotechnol 16:231-238 
2. Fabre CE, Santerre AL, Loret MO, Baberian R, Paresllerin A, Goma G, Blanc PJ (1993) Production and food applications of the red pigment of Monascus rubber. J Food Sci 58:1099-1110

3. Lee YK, Chen DC, Chauvatcharin S, Seki T, Yoshida T (1995) Production of Monascus pigments by a solid-liquid state culture method. J Ferment Bioeng 2:21-26

4. Kim HL, Kim HJ, Oh HJ, Shin CS (2002) Morphology control of Monascus cell and scale up of pigment fermentation. Process Biochem 38:649-655

5. Blanc PJ, Loret MO, Goma G (1995) Production of citrinin by various species of Monascus. Biotechnol Lett 17:291-294

6. Pisareva E, Savov V, Kujumdzieva A (2005) Pigments and citrinin biosynthesis by fungi belonging to genus Monascus. Z Naturforsch C 60:116-120

7. Blanc PJ, Laussac JP, Lebars J, Lebars P, Loret MO, Pareilleux A, Prome D, Prome JC, Santerre AL, Goma G (1995) Characterization of monascidin A from Monascus as citrinin. Int J Food Microbiol 27:201-213

8. Li ZQ, Guo F (2004) A further studies on the species of Monascus. Mycosystema 23:1-6

9. Kim JY, Kim HJ, Oh JH, Lee $\mathbb{H}$ (2010) Characteristics of Monascus sp. isolated from Monascus fermentation products. Food Sci Biotechnol 19:1151-1157

10. Huang L, Wei PL, Zang R, Xu ZN, Cen PL (2010) High-throughput screening of high-yield colonies of Rhizopus oryzae for enhanced production of fumaric acid. Ann Microbiol 60:287-292

11. Betts Jl, Doig SD, Baganz F (2006) Characterization and application of a miniature $10 \mathrm{~mL}$ stirred-tank bioreactor, showing scale-down equivalence with a conventional $7 \mathrm{~L}$ reactor. Biotechnol Prog 22(3):681-688

12. Gao H, Liu M, Zhou XL, Liu JT, Zhuo Y, Gou ZX, Xu B, Zhang WQ, Liu XY, Luo AQ, Zheng CS, Chen XP, Zhang LX (2010) Identification of avermectin-high-producing strains by HTS methods. Appl Microbiol Biotechnol 85:1219-1225

13. Harms P, Kostov Y, French JA, Soliman M, Anjanappa M, Ram A, Rao G (2006) Design and performance of a 24-station high throughput microbioreactor. Biotechnol Bioeng 93:6-13

14. Chen A, Chitta R, Chang D, Amanullah A (2008) Twenty-four well plate miniature bioreactor system as a scale-down model for cell culture process development. Biotechnol Bioeng 102(1):148-160

15. Buchs J (2001) Introduction to advantages and problems of shaken cultures. Biochem Eng J 7:91-98

16. Du Toit EA, Rautenbach M (2000) A sensitive standardised micro-gel well diffusion assay for the determination of antimicrobial activity. J Microbiol Methods 42:159-165

17. Kumar MS, Kumar PM, Sarnaik HM, Sadhukhan AK (2000) A rapid technique for screening of lovastatin-producing strains of Aspergillus terreus by agar plug and Neurospora crassa bioassay. J Microbiol Methods 40:99-104

18. Hermann R, Lehmann M, Büchs J (2003) Characterization of gas-liquid mass transfer phenomena in microtiter plates. Biotechnol Bioeng 81(2):178-186

19. Bujalski JM, Jaworski Z, Bujalski W, Nienow AW (2002) The influence of the addition position of a tracer on CFD simulated mixing times in a vessel agitated by a Rushton turbine. Chem Eng Res Des 80:824-831

20. Lane GL, Schwarz MP, Evans GM (2005) Numerical modelling of gas-liquid flow in stirred tanks. Chem Eng Sci 60:2203-2214

21. Min J, Gao ZM, Shi LT (2005) CFD simulation of mixing in a stirred tank with multiple hydrofoil impellers. Chin J Chem Eng 13:583-588

22. Hristov HV, Mann R, Lossev V, Vlaev SD (2004) A simplified CFD for three dimensional analysis of fluid mixing, mass transfer and bioreaction in a fermenter equipped with triple novel geometry impellers. Food Bioprod Process 82:21-34

23. Raimondi MT, Moretti M, Cioffi M, Giordano C, Boschetti F, Lagana K, Pietrabissa R (2006) The effect of hydrodynamic shear on 3D engineered chondrocyte systems subject to direct perfusion. Biorheology 43:215-222

doi:10.1186/s40643-014-0016-6

Cite this article as: Tan et al: High-throughput system for screening of Monascus purpureus high-yield strain in pigment production. Bioresources and Bioprocessing 2014 1:16.

\section{Submit your manuscript to a SpringerOpen ${ }^{\odot}$ journal and benefit from:}

- Convenient online submission

- Rigorous peer review

- Immediate publication on acceptance

- Open access: articles freely available online

- High visibility within the field

- Retaining the copyright to your article

Submit your next manuscript at $\gg$ springeropen.com 